\title{
OPTIMALISASI PERSEDIAAN BAHAN BAKAR SOLAR PADA PT MACINDO MITRA RAYA DENGAN METODE ECONOMIC ORDER QUANTITY (EOQ)
}

\author{
M. E. Rizanjani ${ }^{1}$, A. Sahari² dan Andri ${ }^{3}$. \\ 1,2,3Program Studi Matematika Jurusan Matematika FMIPA Universitas Tadulako \\ Jalan Soekarno-Hatta Km. 09 Tondo, Palu 94118, Indonesia. \\ 1eliarizanjani94@yahoo.com, 2agusmansahari@yahoo.com, 3desylusiyanti@yahoo.co.id
}

\section{ABSTRACK}

PT. Macindo Mitra Raya is a type of diesel oil (BBM) industrial company that supplies diesel fuel to full fill industrial nesercity, where one of the prices of diesel is the cost of inventory that needs to be managed. This study aims to determine the total cost of diesel fuel type inventories and determine the amount of stock of diesel fuel that is economical at PT. MACINDO MITRA RAYA through the Economic Order Quantity (EOQ) method. To calculation the number of economical orders, the formula $\sqrt{\frac{2 D S}{H}}$ is used. Then to determine the total fuel inventory cost, the formula $\sqrt{2 D S H}$ is used where $\mathrm{D}$ is the annual fuel order, $\mathrm{S}$ as the order ordering cost and $\mathrm{H}$ as the total ordering cost per message. From the results of the study indicate that the economical order for PT.Macindo Mitra Raya is 48,814.07 liters and the amount of inventory costs is Rp. 1,199,039,533. From the results obtained from the research conducted it has implications for the greatest efficiency in the cost of inventory of PT. Macindo Mitra Raya.

Keyword : Economic Order Quantity, Fuel Oil, Solar, Stock Supplly.

\section{ABSTRAK}

PT. Macindo Mitra Raya adalah perusahaan industri minyak (BBM) jenis solar yang menyediakan persediaan solar untuk memenuhi kebutuhan industri tertentu, dimana salah satu harga solar adalah biaya persediaan yang perlu dikelola. Penelitian ini bertujuan untuk menentukan biaya total persediaan BBM jenis solar dan menentukan jumlah persediaan BBM jenis solar yang ekonomis pada PT. MACINDO MITRA RAYA melalui metode Economic Order Quantity (EOQ). Untuk menghitung jumlah pemesanan ekonomis, digunakan rumus $\sqrt{\frac{2 D S}{H}}$, Kemudian untuk menentukan total biaya persediaan bahan bakar digunakan rumus $\sqrt{2 D S H}$ dimana $\mathrm{D}$ sebagai jumlah pemesanan bahan bakar pertahun, $\mathrm{S}$ sebagai biaya pemesanan perpesan dan $\mathrm{H}$ sebagai jumlah biaya pemesanan per pesan. Dari hasil penelitian menunjukkan bahwa pesanan yang ekonomis untuk PT.Macindo Mitra Raya adalah 48.814,07 liter dan besarnya biaya persediaan sebanyak Rp. 1.199.039.533. Dari hasil yang didapat dari penelitian yang dilakukan memberikan implikasi terhadap efisiensi terbesar pada biaya persediaan PT.Macindo Mitra Raya.

Kata kunci : Economic Order Quantity, BBM, Solar, Persediaan. 


\section{PENDAHULUAN}

\subsection{Latar Belakang}

PT Macindo Mitra Raya yang berdiri sejak awal tahun 1980-an adalah perusahaan yang menyedikan jasa transportasi dan distribusi minyak ( $B B M$ ) industri dari Pertamina ke industriindustri besar di Indonesia. PT Macindo Mitra Raya berperan penting dalam proyek yang dikerjakan oleh industri-industri yang ada di Sulawesei dan juga memiliki peran dalam perkembangan pembangunan di Sulawesi Tengah khususnya bagi daerah-daerah yang menjadi sentra industri. Keberlangsungan suatu proyek pembangunan sangat bergantung pada persediaan bahan bakarnya dimana persediaan bahan bakar untuk alat kerja perusahaan harus memenuhi kuota hingga suatu proyek selesai. Salah satu bahan bakar yang di distribusikan oleh PT Macindo Mitra Raya adalah bahan bakar solar. Bahan bakar solar biasanya dipakai oleh alat-alat berat dalam proyek-proyek pembangunan sehingga tersediannya bahan bakar solar pada proyek yang membutuhkan tenaga alat berat seperti proyek pembangunan jalan raya, jembatan, drainase, dan lain-lain sangatlah penting. Bahan bakar solar merupakan salah satu kebutuhan primer pada suatu proyek yang membutuhkan tenaga alat berat sehingga keberlansungan suatu proyek sangat bergantung pada perserdiaan BBM jenis solar.

Jumlah persediaan yang baik adalah jumlah persediaan yang tidak dalam jumlah terlalu banyak dan tidak terlalu sedikit karena jumlah persediaan yang terlalu banyak atau terlalu sedikit keduanya mengandung resiko. Terlalu sedikit dapat berpeluang terjadinya kehabisan persediaan yang berakibat menggangu sistem kerja alat proyek, di lain pihak apabila jumlah persediaan terlalu banyak, berakibat terlalu besar modal kerja dengan resiko biaya menjadi tinggi serta resiko terjadinya penyusutan yang merugikan perusahaan. Jadi persediaan yang diadakan harus optimum.

Mengingat jumlah persediaan dipengaruhi oleh jumlah pesanan, maka jumlah pesanan harus optimum agar jumlah persediaan optimum. Untuk menentukan hal tersebut dibutuhkan suatu metode, salah satunya adalah Metode Economic Order Quantity (EOQ). Pada penelitian sebelumnya, Santi, (2017) menggunakan EOQ untuk optimalisasi persedian bahn bakar minyak industri pada PT Prima Sentosa Alam Lestari. Berdasarkan pembahasan di atas maka penulis tertarik untuk melakukan penelitian dengan judul "Optimalisasi Persediaan Bahan Bakar Minyak Solar Dengan Metode Economic Order Quantity (EOQ)".

\subsection{Tujuan Penelitian}

1. Menentukan biaya total persediaan BBM jenis solar pada PT. MACINDO MITRA RAYA melalui metode Economic Order Quantity (EOQ).

2. Menentukan jumlah pemesanan BBM jenis solar yang ekonomis pada PT. MACINDO MITRA RAYA melalui metode Economic Order Quantity (EOQ) 


\section{METODE PENELITIAN}

1. Melakukan studi literatur dengan mengumpulkan materi dan dari buku-buku, artikel, dan jurnal yang didapatkan dari perpustakaan dan internet.

2. Pengambilan data

3. Membangun model matematika, berdasarkan data yang telah diperoleh.

4. Menyelesaikan model matematika tersebut menggunakan metode Economi Order Quantity (EOQ).

5. Menyimpulkan hasil penelitian

\section{HASIL DAN PEMBAHASAN}

\subsection{Data Penelitian}

Dalam pengendalian persediaannya PT. Macindo Mitra Raya melakukan pemesanan BBM setiap hari dengan kuantitas pemesanan tetap berdasarkan rata-rata kebutuhan pemakaian BBM yaitu;

1) Penampungan BBM jenis solar sebesar 125.000 liter.

2) Mempunyai 10 mobil penampung yang kapasitasnya 5.000 liter.

3) Mmempunyai 4 mobil tangki.

a. Dimana terdapat 2 mobil tengki yang kapasitasnya 10.000 liter.

b. 2 mobil yang kapasitasnya 20.000 liter.

Metode perhitungan EOQ dilakukan untuk mengetahui berapa jumlah kuantitas pemesanan dan total biaya persediaan optimum dari biaya-biaya operasionalnya (P.Siagian, 1987). PT Macindo Mitra Raya melakukan pemesana bahan bakar terhitung setiap hari. Data yang diperoleh tersebut dapat dilihat pada Tabel 1.

Tabel 1 : Tabel Persediaan BBM (Periode Tahun 2017)

\begin{tabular}{|c|l|c|}
\hline No. & \multicolumn{1}{|c|}{ BULAN } & PERSEDIAAN (Liter) \\
\hline 1. & Januari & 800.000 \\
\hline 2. & Februari & 780.000 \\
\hline 3. & Maret & 745.000 \\
\hline 4. & April & 830.000 \\
\hline 5. & Mei & 880.000 \\
\hline 6. & Juni & 735.000 \\
\hline 7. & Juli & 815.000 \\
\hline 8. & Agustus & 742.000 \\
\hline 9. & September & 773.000 \\
\hline
\end{tabular}




\begin{tabular}{|c|l|c|}
\hline 10. & Oktober & 960.000 \\
\hline 11. & November & 845.000 \\
\hline \multirow{2}{*}{12.} & Desember & 850.000 \\
\hline \multirow{2}{*}{} & Jumlah (D) & 9.755 .000 \\
\cline { 2 - 3 } & Rata-rata & 812,916 \\
\hline
\end{tabular}

Sumber : PT. Macindo Mitra Raya

Pada tahun 2017 PT Macindo Mitra Raya melakukan pemesanan bahan bakar setiap hari dengan jumlah rata-rata setiap bulan yaitu 812.916 liter. Pada umumnya persediaan bahan bakar pada PT Macindo Mitra Raya tahun 2017 relatif normal yaitu diatas 742.000 liter per bulan.Untuk lebih jelasnya dapat dilihat pada Gambar 1.

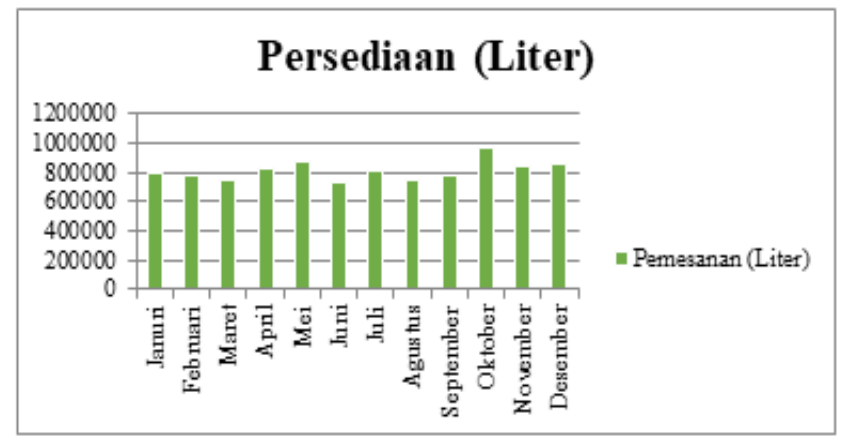

Gambar 1 : Grafik Persediaan BBM

\subsection{Analisis Pengendalian Persediaan Berdasarkan Kebijakan Perusahaan}

\subsubsection{Komponen Biaya Persediaan}

Berdasarkan analisis biaya persediaan bahan bakar minyak (BBM) industri pada PT. Macindo Mitra Raya terdapat tinga komponen biaya, yaitu biaya pemesanan, biaya penyimpanan, dan harga Solar perliter. Biaya pemesanan merupakn biaya yang dikeluarkan dalam rangka pengadaan solar untuk menjaga tersedianya persediaan solar, sedangkan biaya penyimpanan yang dilakukan PT. Macindo Mitra Raya yaitu biaya yang di timbulkan akibat dari biaya perawatan fasilitas.

Tabel 2 : Data Biaya Pemesanan Per satu kali pesan

\begin{tabular}{|l|l|}
\hline \multicolumn{1}{|c|}{ Jenis Biaya } & \multicolumn{1}{c|}{ Jumlah } \\
\hline Ekspedisi dan Administrasi & Rp. 1.500 .000 \\
\hline Pembuatan PO & Rp. 500.000 \\
\hline Biaya Bongkar Muat & Rp. 1.000 .000 \\
\hline Total (S) & Rp. 3.000 .000 \\
\hline
\end{tabular}

Sumber : Hasil wawancara dengan PT Macindo Mitra Raya 
Berdasarkan Tabel 2 di atas dapat di jelaskan bahwa, biaya pemesanan adalah biaya yang dikeluarkan dalam rangka pengadaan BBM untuk menunjang tersedianya persediaan bahan bakar di PT Macindo Mitra Raya.

Tabel 3 : Data Biaya Penyimpanan Per satu kali pesan

\begin{tabular}{|l|l|}
\hline \multicolumn{1}{|c|}{ Jenis Biaya } & \multicolumn{1}{c|}{ Jumlah } \\
\hline Biaya perawatan tangki & Rp. $7.676,063$ \\
\hline Biaya Susut & Rp. $3.454,228$ \\
\hline Gaji karyawan & Rp. $13.433,11$ \\
\hline Total $(\mathbf{H})$ & Rp. $\mathbf{2 4 . 5 6 3 , 4 0}$ \\
\hline
\end{tabular}

Sumber : Hasil wawancara dengan PT Macindo Mitra Raya

Berdasarkan Tabel 3 di atas dapat djelaskan bahwa,biaya penyimpanan adalah semua pengeluaran yang timbul akibat penyimpanan BMM Pada PT Macindo Mitra Raya

Tabel 4 : Data Persediaan Per satu kali pesan

\begin{tabular}{|l|l|}
\hline Biaya pemesanan & Rp. 3.000 .000 \\
\hline Biaya penyimpanan & Rp. $24.563,40$ \\
\hline Harga perliter & Rp. 9.500 \\
\hline Lead Time/waktu tunggu & 1 hari \\
\hline
\end{tabular}

Dalam melakukan produksinya terlihat biaya-biaya persediaan yang dilakukan PT Macindo Mitra Raya yaitu biaya pemesanan (S) bahan bakar dalam sekali pesan sebesar Rp. 3.000.000 per pesan. Sedangkan biaya penyimpanan $(H)$ bahan bakar yaitu Rp. 24.563,40 per pesan, dan BBM (C) adalah Rp.9.500 per liter. Dalam melakukan pemesanan bahan bakar, perusahan memiliki Waktu Tunggu (waiting time) (L) selama 1 hari untuk menunggu kedatangan bahan bakar yang dipesan, yang kemudian di jual kepada para pelanggan.

\subsubsection{Frekuensi Pemesanan}

Frekuensi pemesanan merupakan banyaknya pemesanan bahan bakar dalam satu periode (satu tahun) yang dilakukan oleh PT Macindo Mitra Raya. Dalam hal ini PT Macindo Mitra Raya melakukan pemesanan bahan bakar setiap hari selama satu tahun dengan asumsi dalam satu tahun terdapat 365 hari dikurangi hari libur perusahaan dalam satu tahun yaitu 53 hari atau tiap bulannya terdiri dari 4 hari libur yaitu setiap hari minggu. Jadi frekuensi pemesanan bahan bakar yang dilakukan PT Macindo Mitra Raya adalah sebanyak 312 kali dalam satu tahun. 


\subsubsection{Total Biaya Persediaan Menurut Kebijakan Perusahaan}

1. Jumlah Pemesanan Bahan Bakar Per Pesan

Menurut total biaya persediaan yang dikeluarkan oleh PT Macindo Mitra Raya. Sebelum menghitung total biaya persediaan, terlebih dahulu dihitung jumlah pemesanan per pesan $(Q)$ dengan cara menghitung jumlah pemesanan per tahun (D) dibagi dengan frekuensi pemesanan per tahun $(F)$, rumusnya sebagai berikut:

$$
\begin{aligned}
Q \quad & =\frac{D}{F} \\
& =\frac{9.755 .000}{312} \\
& =31.266,025 \text { liter per pesan }
\end{aligned}
$$

Jadi, diperoleh besarnya jumlah pemesanan bahan bakar yang dilakukan oleh PT Macindo Mitra Raya dalam sekali pesan yaitu sebesar $R p$. 31.266,025 liter per pesan.

\section{Total Biaya Persediaan Perusahaan}

Total biaya persediaan didapatkan dengan menjumlahkan biaya pemesanan per tahun dengan biaya penyimpanan pertahun. Agar dapat menghitung total biaya persediaan maka yang harus diketahui terlebih dahulu adalah:

1) Jumlah pemesanan bahan bakar per tahun $(D)=9.755 .000$ liter

2) Jumlah pemesanan per pesan $(Q)=31.266,025$ liter

3) Biaya pemesanan per pesan (S) = Rp. 3.000.000

4) Biaya penyimpanan per pesan $(H)=$ Rp. $24.563,40$

Dengan mengetahui biaya-biaya persediaan diatas, maka dapat dihitung total biaya persediaan perusahaan sebagai berikut:

Biaya pemesanan per tahun $=\frac{D}{Q} S$

$$
\begin{aligned}
& =\frac{9.755 .000}{31.266,025} 3.000 .000 \\
& =935.999 .870
\end{aligned}
$$

Biaya penyimpanan pertahun $=\frac{Q}{2} H$

$$
\begin{aligned}
& =\frac{31 \cdot 266,025}{2} 24 \cdot 563,40 \\
& =384 \cdot 000 \cdot 000,7
\end{aligned}
$$

Dari hasil perhitungan diatas dapat diketahui biaya pemesanan per tahun yaitu $R p .935,999,870$,- dan biaya penyimpanan per tahun yaitu $R p .384 .000 .000,7-$.

Untuk mengetahui total biaya persediaan perusahaan dapat dihitung dengan menggunakan rumus sebagai berikut: 


$$
\begin{aligned}
\text { TIC } & =\left[\frac{D}{Q} S\right]+\left[\frac{Q}{2} H\right] \\
& =935,999,870+384.000 .000,7 \\
& =R p \cdot 1.319 .999 .870,7
\end{aligned}
$$

Dari perhitungan dapat diketahui total biaya persediaan yang harus ditanggung perusahaan selama setahun adalah sebesar $R p .1 .319 .999 .870,7$.

\subsection{Analisis Pengendalian Persediaan Berdasarkan Metode EOQ}

\subsubsection{Menghitung Jumlah Pemesanan Ekonomis Menurut Metode EOQ}

Untuk menghitung pemesanan bahan bakar yang ekonomis terlebih dahulu harus diketahui jumlah pemesanan bahan bakar pertahun (D), jumlah biaya pemesanan per pesan (S), dan jumlah biaya pemesanan per pesan (H). PT. Macindo Mitra Raya melakukan pemesanan bahan bakar solar dalam satu tahun sebesar 9.755 .000 liter dengan rata-rata pemesanan per pesan sebesar 31.266,025 liter. Dengan biaya pemesanan sebesar $R p .3 .000 .000$ per pesan dan biaya penyimpanan sebesar $R p .24 .563,40$ per pesan (Gitosudarmo 1999).

Sehingga dengan biaya-biaya tersebut dapat digunakan untuk menghitung jumlah pemesanan bahan bakar miyak solar (BBM) yang ekonomis pada PT Macindo Mitra Raya

$$
\begin{aligned}
Q^{*} & =\sqrt{\frac{2 D S}{H}} \\
& =\sqrt{\frac{2(9.755 .000)(3.000 .000)}{24.563,40}} \\
& =\sqrt{\frac{58.530 .000 .000 .000}{24.563,40}} \\
& =\sqrt{2.382 .813 .126} \\
& =48.814,07 \text { liter }
\end{aligned}
$$

Dari perhitungan pada persamaan diatas dapat diketahui jumlah pemesanan bahan bakar yang ekonomis menurut metode EOQ untuk PT Macindo Mitra Raya adalah sebesar 48.814,07 liter per pesan.

\subsubsection{Frekuensi Pemesanan}

Dengan mengetahui jumlah pemesanan bahan bakar yang ekonomis maka frekuensi pemesanan juga dapat diketahui. Untuk menghitung frekuensi pemesanan bahan bakar pertahun dilakukan dengan membagi jumlah pemesanan bahan bakar pertahun (D) dengan jumlah pemesanan bahan bakar yang ekonomis $\left(Q^{*}\right)$. PT Macindo Mitra Raya melakukan pemesanan bahan bakar dalam satu tahun sebesar 9.755 .000 liter dengan rata-rata pemesanan perhari sebesar $31.266,025$ liter. Sedangkan peritungan menggunakan metode 
EOQ pemesanan bahan bakar yang ekonomis perpesan sebesar 48.814,07 liter. Dalam menghitung frekuensi pemesanan digunakan rumus sebagai berikut:

$$
\begin{aligned}
F \quad & =\frac{D}{Q^{*}} \\
& =\frac{9.755 .000}{48.814,07} \\
& =199,83 \sim 200 \text { kali. }
\end{aligned}
$$

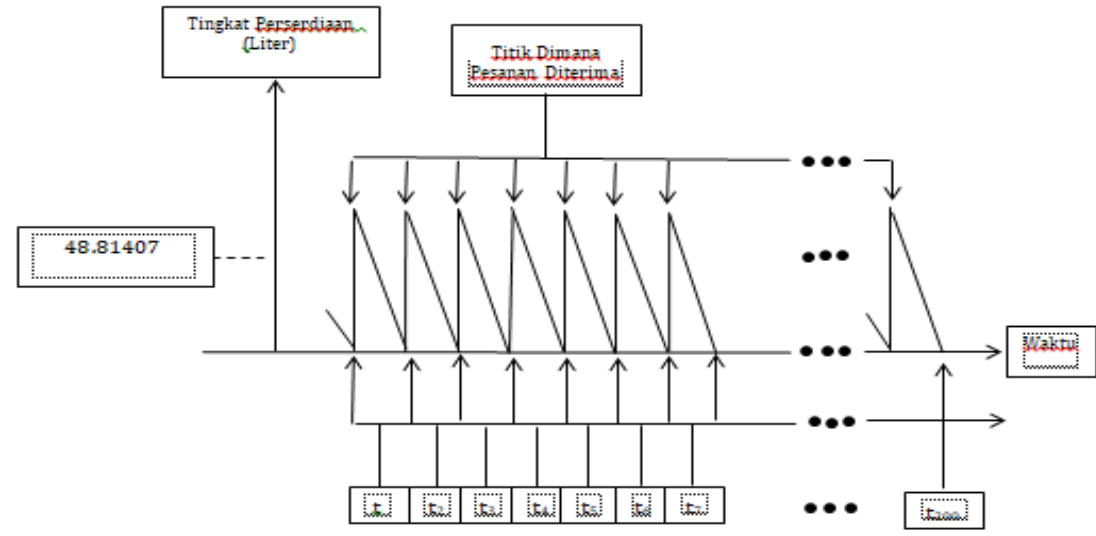

Gambar 2 : Grafik EOQ (Economic Order Quantity)

Berdasarkan grafik diatas, PT. Macindo Mitra Raya harus melakukan pemesanan bahan bakar solar sebanyak 48.814,07 liter ketika suatu pesanan diajukan. Hal ini akan menyebabkan bahwa dalam satu tahun PT. Macindo Mitra Raya akan melakukan sebanyak $=\frac{9.755 .000}{48.814,07}=200$ kali pemesanan.

\subsubsection{Persediaan Pengaman (Safety Stock)}

Dalam metode EOQ persediaan pengaman harus dilakukan agar proses produksi tetap berjalan. Dalam penelitian ini menghitung persediaan pengaman digunakan metode statistik dengan membandingkan rata-rata pemesanan bahan bakar dengan pengaman bahan bakar yang sesungguhnya kemudian dicari penyimpangannya, perhitungan standar deviasi dapat dilihat pada Tabel 5.

Tabel 5 : Perhitungan Standar Deviasi

\begin{tabular}{|c|l|c|c|c|}
\hline NO & \multicolumn{1}{|c|}{ BULAN } & PASOKAN $(X)$ & $(X-\bar{X})$ & $(X-\bar{X})^{2}$ \\
\hline 1. & Januari & 800.000 & -12.916 & 166.823 .056 \\
\hline 2. & Februari & 780.000 & -32.916 & 1.083 .463 .056 \\
\hline 3. & Maret & 745.000 & -67.916 & 4.612 .583 .056 \\
\hline 4. & April & 830.000 & 17.084 & 291.863 .056 \\
\hline 5. & Mei & 880.000 & 67.084 & 4.500 .263 .056 \\
\hline 6. & Juni & 735.000 & -77.916 & 6.070 .903 .056 \\
\hline
\end{tabular}




\begin{tabular}{|c|l|c|c|c|}
\hline 7. & Juli & 815.000 & 2.084 & 4.343 .056 \\
\hline 8. & Agustus & 742.000 & -70.916 & 5.029 .079 .056 \\
\hline 9. & September & 773.000 & -39.916 & 1.593 .287 .056 \\
\hline 10. & Oktober & 960.000 & 147.084 & 21.633 .703 .056 \\
\hline 11. & November & 845.000 & 32.084 & 1.029 .383 .056 \\
\hline \multirow{2}{*}{12.} & Desember & 850.000 & 37.085 & 1.375 .223 .056 \\
\hline \multirow{2}{*yyyy}{} & Jumlah & 9.755 .000 & & 47.390 .916 .672 \\
\cline { 2 - 5 } & Rata-rata & 812.916 & & \\
\hline
\end{tabular}

$$
\begin{aligned}
\sigma & =\sqrt{\frac{\sum(x-\bar{x})^{2}}{n}} \\
& =\sqrt{\frac{47.390 .916 .672}{12}} \\
& =62.843,01 \text { liter }
\end{aligned}
$$

Berdasarkan perhitungan penggunaan bahan bakar di atas diperoleh standar deviasi yaitu $\sigma=$ $62.843,01$. dan PT Macindo Mitra Raya menggunakan batas toleransi $\alpha=5 \%$ dibawah perkiraan dan diperoleh nilai standar normal deviasi (Z) adalah 1.65. Maka besarnya persediaan pengaman (safety stock) bahan bakar dapat dihitung dengan rumus sebagai berikut:

$S S=Z \sigma$

Dimana, SS = safety stock (persediaan pengaman),

$\mathrm{Z}=$ standar deviasi,

$\sigma=$ standar deviasi normal,

SS $\quad=Z \sigma$

$=1,65 \times 62.843,01$

$=103.690,95$ liter

Dari hasil perhitungan di atas dapat diketahui persediaan pengaman (Safety stock) bahan bakar yang harus disediakan oleh PT. Macindo Mitra Raya 2017 adalah 103.690,95 liter.

\subsubsection{Pemesanan Kembali (Reorder Poin)}

Saat pemesanan kembali atau Reorder Poin $(R)$ adalah saat dimana perusaaan harus melakukan pemesanan bahan bakar kembali, sehingga penerimaan bahan bakar yang dipesan dapat tepat waktu, karena dalam melakukan pemesanan bahan bakar tidak dapat langsung diterima hari itu juga. Besarnya sisa bahan bakar yang masih tersisa hingga perusahaan harus melakukan pemesanan kembali adalah sebesar $(R)$ yang tela dihitung. Pemesanan kembali dapat dihitung dengan menjumlahkan penggunaan selama waktu tenggang ditambah dengan persediaan pengaman (Assauri 2004). 
Rata-rata penggunaan bahan bakar perhari (D) pada PT. Macindo Mitra Raya diperoleh dari jumlah pemesanan pertahun dibagi dengan jumlah hari dalam satu tahun yang diasumsikan bahwa dalam satu tahun berjumlah 312 (hari kerja). Jumlah pemesanan pertahun yang dilakukan PT. Macindo Mitra Raya sebesar 9.755.000 liter. Maka rata-rata pemesanan bahan bakar solar adalah $\frac{9.755 .000}{312}=31,266.025$ liter per pesan. Dalam melakukan pemesanan bahan bakar PT. Macindo Mitra Raya memiliki waktu tenggang (lead time) (L) selama satu hari untuk menunggu kedatangan bahan bakar setelah terjadi pemesanan. Maka titik pemesanan kembali dapat dihitung dengan rumus sebagai berikut:

$$
\begin{aligned}
R & =D L+S S \\
& =(31.266,025 \text { liter } x 1)+103.690,95 \\
& =134.956,975 \text { liter }
\end{aligned}
$$

Dari hasil perhitungan di atas dapat diketahui bahwa perusahaan harus melakukan pemesanan kembali pada saat persediaan BBM berada pada 134.956,975 liter.

\subsubsection{Persediaan Maksimum (Maksimum Inventory)}

Untuk mengetahui besarnya persediaan maksimum dapat dihitung menggunakan rumus sebagai berikut :

$$
\begin{aligned}
\text { Maksimum Inventory } & =S S+Q^{*} \\
& =103.690,95+48.814,07 \\
& =152.505,017 \text { liter. }
\end{aligned}
$$

Jadi, jumlah persediaan maksimum pada perusahaan adalah 152.505,017 liter.

\subsubsection{Total Biaya Persediaan}

Untuk memperoleh total biaya persediaan bahan bakar yang minimal maka diperhitungkan total biaya bahan bakar. Hal tersebut dilakukan untuk mengetahui berapa besar penghematan biaya persediaan dalam perusahaan. Total biaya persediaan merupakan keseluruhan dari biaya-biaya yang timbul dari persediaan yang dikeluarkan oleh perusahaan. Untuk menghitung total biaya persediaan maka harus diketahui terlebih dahulu adalah:

1. Jumlah pemesanan bahan bakar per tahun $(D)=9.755 .000$

2. Jumlah biaya pemesanan per pesan $(S)=R p .3 .000 .000$

3. Jumlah biaya penyimpana per pesan $(H)=R p .24 .563,40$

Dari variabel-variabel di atas dapat dihitung dengan rumus sebagai berikut:

$$
\begin{aligned}
\text { TIC } & =\sqrt{2 D S} H \\
& =\sqrt{2(9.755 .000)(3.000 .000)(24.563,40)} \\
& =1.199 .039 .533
\end{aligned}
$$


Dari perhitungan di atas total biaya persediaan (total inventory cost) perusahaan menggunakan metode EOQ yaitu sebesar $R p .1 .199 .039 .533$

\subsection{Perbandingan Kebijakan Perusahaan Dengan Metode EOQ}

Dari hasil analisis data sebelumnya telah diketahui perbandingan antara jumlah pemesanan bahan bakar, frekuensi pemesanan, dan total biaya persediaan menurut kebijakan perusahaan berbandingan dengan penggunaan metode EOQ. Untuk lebih jelasnya dapat dilihat pada Tabel 6.

Tabel 6 : Perbandingan Kebijakan Perusahaan dengan Metode EOQ

\begin{tabular}{|c|l|c|c|}
\hline NO. & \multicolumn{1}{|c|}{ Keterangan } & Kebijakan Perusahaan & Metode EOQ \\
\hline 1. & Jumlah Pemesanan BBM perpesan & $31.266,03$ liter & $48.814,07$ liter \\
\hline 2. & Total Biaya Persediaan pertahun & $R p .1 .319 .999 .807,7$ & $R p .1 .199 .039 .533$ \\
\hline 3. & Frekuensi Pemesanan & 312 kali pesan & 200 kali pesan \\
\hline 4. & Persediaan Pengaman & - & $103.690,95$ liter \\
\hline 5. & Pemesanan Kembali & - & $134.956,975$ liter \\
\hline 6. & Persediaan Maksimum & - & $152.505,017$ liter \\
\hline
\end{tabular}

Dari Tabel 6 : dapat dilihat perbandingan antara jumlah pemesanan bahan bakar menurut kebijakan perusahaan dengan metode EOQ dimana menurut kebijakan perusaaan jumlah pemesanan bahan bakar sebesar 31.266,025 liter per pesan dengan frekuensi pemesanan sebanyak 312 kali pertahun. Sedangkan menggunakan metode EOQ pemesanan bahan bakar yang ekonomis yaitu sebesar $48.814,07$ per liter per tahun dengan frekuensi pemesanan sebanyak 200 kali per tahun. Terjadi selisih 112 kali pemesanan antara frekuensi pemesanan menurut kebijakan perusahaan dengan metode EOQ. Dengan demikian selisih total biaya persediaan menurut kebijakan dengan menggunakan metode EOQ adalah sebesar $=R p$ 120.960.274. . Maka diketahui penghematan total biaya persediaan perusahaan bila menggunakan metode EOQ per tahun.

\section{KESIMPULAN}

Berdasakan hasil perhitungan yang telah diperoleh,maka dapat di ambil kesimpulan terhadap penerapan Metode EOQ pada PT. Macindo Mitra Raya yaitu, dari hasil penelitian diketahui bahwa jumlah pemesanan bahan bakar minyak (BBM) jenis solar yang ekonomis adalah sebesar 48.814.,07 Liter. Bila dihitung menurut metode $E O Q$, maka diketahui bahwa total biaya persediaan bahan bakar minyak (BBM) jenis solar yang dikeluarkan oleh perusahaan adalah sebesar Rp 1.199.039.533 sedangkan kebijakan perusahaan $R p .1 .319 .999 .870,7$, dengan selisih antara keduanya adalah sebesar Rp. 120.960.274. 


\section{DAFTAR PUSTAKA}

[1] Assauri, S, Manajemen Produksi dan Operasi Edisi Revisi. Lembaga Penerbitan Fakultas Ekonomi Universitas Indonesia, 2004, Jakarta.

[2] Gitosudarmo, Manajemen Keuangan Edisi 3, BPFE (Badan Penerbitan Fakultas Ekonomi), 1999, Yogyakarta.

[3] Santi, Menggunakan EOQ Untuk Optimalisasi Persediaan Bahan Bakar Minyak Industri Pada PT Prima Sentosa Alam Lestari, 2017, Universitas Tadulako.

[4] Siagian, P, Penelitian Operasional, 1987, Universitas Indonesia. 